\title{
Risk analysis of power information control system based on smart grid security standardization
}

\author{
Pil Sung Woo ${ }^{a}$, Balho H. Kim ${ }^{\text {b* }}$ \\ ${ }^{a}$ Korea Electric Safety Corporation, 12, Ogong-ro, lseo-myeon, Wanju-gun, Jeollabuk-do, 55365, Rep. of Korea \\ ${ }^{b}$ Hongik University, 94, Wausan-ro, Seoul, 04066, Rep. of Korea
}

\begin{abstract}
The smart grid has emerged to meet the rapidly increasing power demand and solve environmental problems through sustainable development. Advanced power networks are being developed to improve the efficiency of power system operation and energy utilization. The advancement of power networks enables us to collect power information in real time, build a database, and optimally control it by utilizing various applications of organically constructed energy management systems. Currently, the rapid change in power infrastructure necessitates security, and the establishment of a cyber security system is essential. Therefore, this paper analyzes the functions of the power information control systems and calculates the risk level for each component by applying the security risk estimation criteria in the Korean Smart Grid security standard (SGSF-121-1-1).
\end{abstract}

Keywords: Smart grid security standard, Power system, Risk assessment, Power information constrol system, Cyber security

\section{Introduction}

The power industry is facing various environmental changes both within and outside the country. Changes in the infrastructure of the power industry due to the construction of a smart grid and the activation of new and renewable energy have inevitably driven the technological advancement of the power information control system [1]. This technological advancement has improved the efficiency of power system operation and produced various issues in the power industry. For example, when a smart grid is constructed and operated, the power system will be exposed to various cyber threats in the information technology (IT) field [2]. Furthermore, cyber attacks are increasing in key global industries. In 2014, a Korean anti-nuclear weapons group (Who Am I) leaked the internal information of Korea Hydro \& Nuclear Power Co., Ld. (KHNP) through cyber attacks using malicious codes in an e-mail [3]. In the same year, the world's largest hacking event (DEFCON) announced a variety of hacking methods for intelligent watt-hour meters, and demonstrated that watt-hour meters are actually vulnerable to security by introducing simple information leaks to more complex methods of acquisition devices [4]. In 2015, a cyber attack in Ukraine caused a malicious code to spread to the internal network of a power plant, resulting in the suspension of the power information control system. This incident cut off the power supply to 80,000 households [5]. Owing to the physical characteristics of electricity, a power system requires strong real-time features and a high level of availability, and the cyber security problem is likely to cause greater complex, large damage than in the existing IT field. Therefore, it is vital to establish a security system suitable for the smart grid. This paper analyzes the function of each component of the power information control system and calculates the risk of each component by applying the security risk estimation criteria proposed in the smart grid security standard of South Korea (SGSF-121-1-1).

\section{Structure of Power Information Control System}

The components of the power information control system are defined as EMS (Energy Management

\footnotetext{
* Manuscript received April 23, 2018; revised January 8, 2019.
}

doi: 10.12720 /sgce.8.2.140-148 
System), SCADA (Supervisory Control And Data Acquisition System), MTU (Master Terminal Unit), RTU (Remote Terminal Unit), and FD (Field Device), and the functions of each component were analyzed [6]. Figure 1 illustrates the structure of the power information control system.

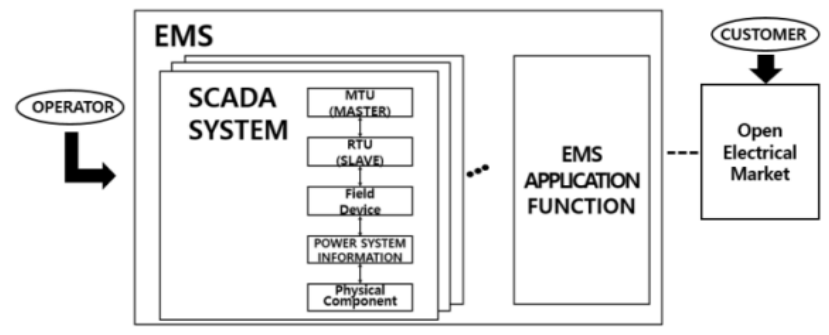

Fig. 1. Structure of power information control system.

\subsection{EMS}

EMS is the main agent that performs the core functions of power information control system (monitoring, control, analysis, planning, etc.) and is in charge of the optimum system operation based on an organic combination of diverse application programs. EMS is composed of a SCADA system, generation control and planning application program, power system analysis application program, etc. It plays an important role in the operation of power systems by regularly performing system stability evaluations and credible accident analyses based on an off-line study.

\subsection{SCADA}

SCADA system can be seen as the concept of EMS's sub-routine, which consists of MTU and RTU to control the power plant and substation of power system. First, the basic function of SCADA is to collect general generation, transmission, and distribution data from RTU. Based on the collected data, power plants and substations that are organically connected with EMS are controlled. The SCADA system structure generally has one or more MTU and subordinate MTUs and RTUs exist under the main MTU.

\section{3. $M T U$}

MTU is a control system that is equivalent to the brain of the SCADA system. It is a control system that has an active input and output system and enables a real-time monitoring and control of the power system through the connected RTU. In short, it collects information transmitted from the RTU for delivery to the operator in the control room and simultaneously enables the RTU to fulfill the operator's order.

\section{4. $R T U$}

RTU is a passive control system that controls on-site equipment at the command of the main MTU and processes analog power information detected from the on-site equipment into a condition available for digital communication through digital signal processing. In most cases, RTUs are located in physically separated areas. To collect the power information of all the areas from each piece of on-site equipment, the RTU is installed in a dispersed manner, over a wide area.

\section{5. $F D$}

The FD plays the role of connecting the physical layer and the power information control layer of a power system. It is subject to the final control of the main MTU and is the equipment that collects the essential information of the power system. This essential information includes the status value (circuit breaker, disconnector, ground switch, open/shut state of valves, etc.), control value (on/off condition of different power equipment and IT equipment), measurement value (pressure, fluid pressure, voltage, current, phase angle, frequency, etc.). 


\section{Criteria for Estimating Risk from Identification of Security Threats}

This study uses the risk estimation method of the smart grid security standard (SGSF-121-1-1) established in South Korea in 2014 [7], and this chapter summarizes the risk estimation criteria presented in the standard. This standard provides a procedure for ensuring the security of smart grid standards, which is applied to smart grid standards that require minimum security functions and interoperability to ensure security.

\subsection{Identification of security targets}

The smart grid security standard proposes identification of three types of security targets: security targets based on the objects of standardization; security targets based on the risk estimation criteria; and security targets based on communication, network, and data characteristics. If any system meets one of these three criteria for identification, its security must be ensured. To estimate the risk of a smart grid, this study adopts the second method, which is to identify the security targets based on risk estimation criteria. The criteria for identification are the risks of availability, integrity, and confidentiality, which are outlined in Table 1.

Table 1. Criteria for identification of targets for standardization based on risk criteria

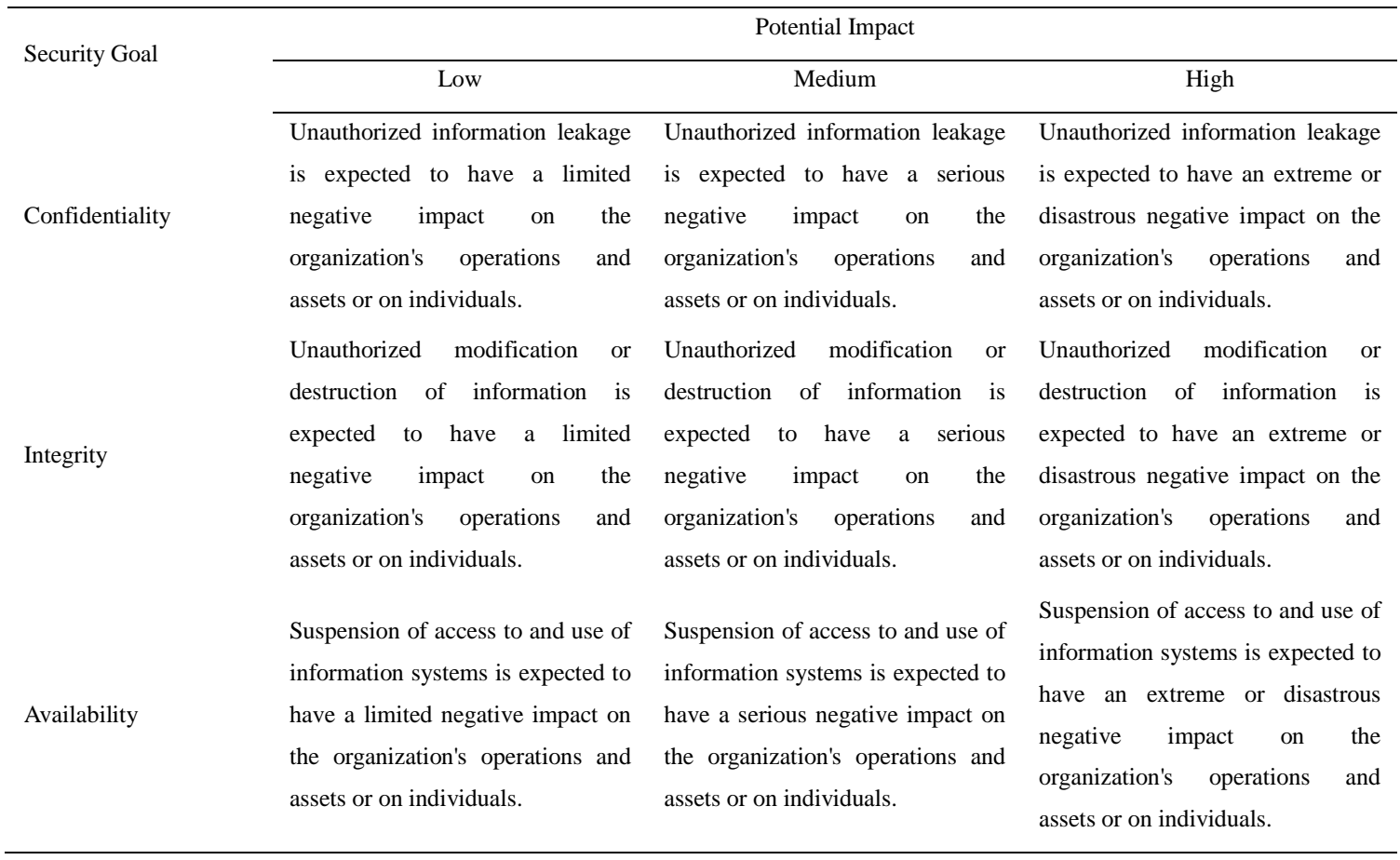

\subsection{Identification of security threats}

The smart grid security standard presents 11 security threats and recommends that smart grid standard developers should estimate risk through the identification of security threats. Table 2 lists the 11 security threats presented in this standard, and the identification criteria for the major security threats defined in the standard are as follows. First, the damage of information and its ripple effects are outlined in Table 3, which are the criteria for analyzing the threat of security violation against information from (T1) through (T6) of the 11 security threats. Table 4 lists the evaluation criteria for identification of physical security threats. Table 5 defines the criteria for the importance of the standard targets. Finally, Table 6 classifies 11 security threats according to the estimation of risk in terms of confidentiality, integrity, and availability for five standard targets. 
Table 2. Eleven security threats of the smart grid security standard

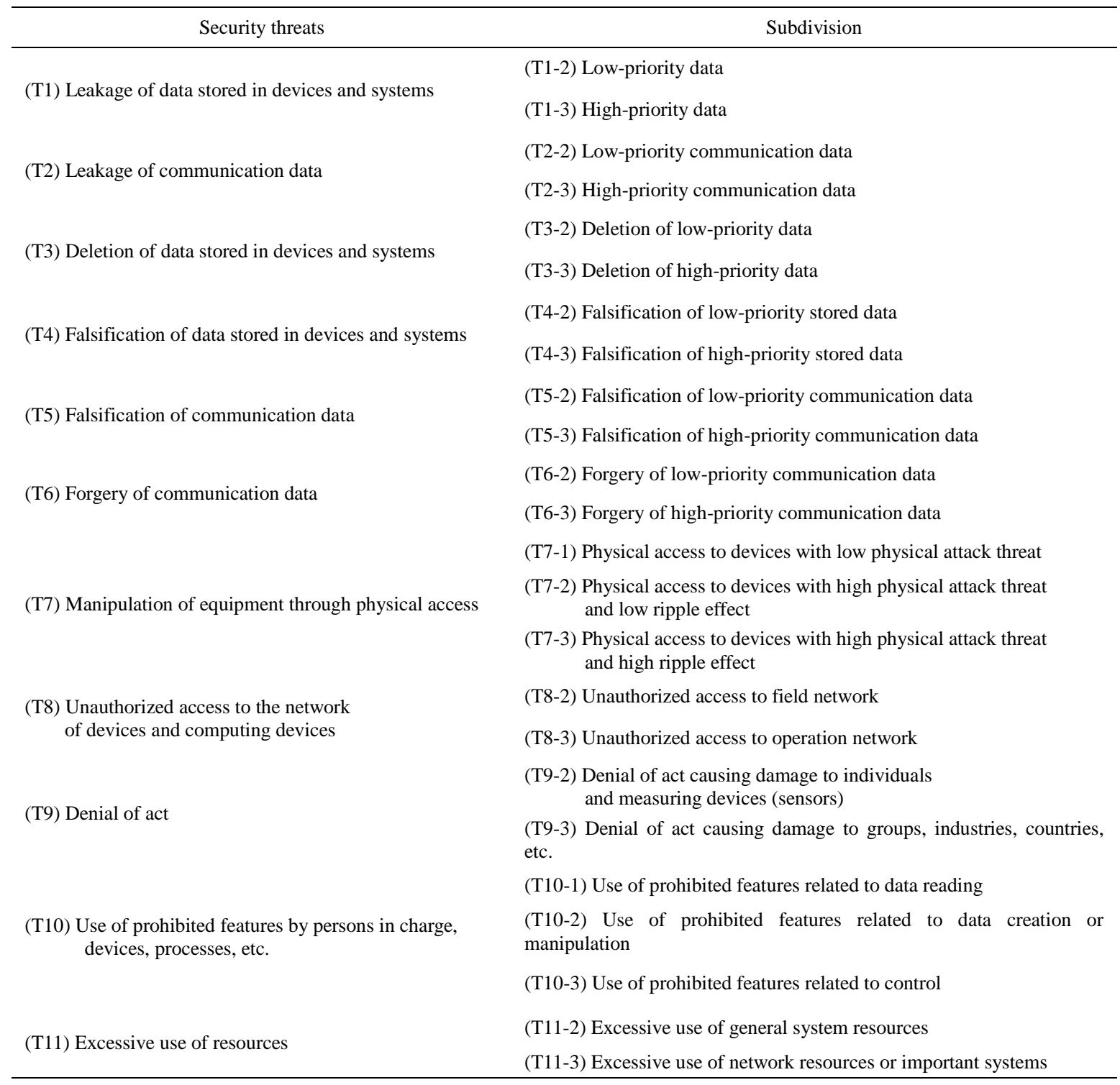

Table 3. Criteria for damages and ripple effects of information

\begin{tabular}{lll}
\hline Grade & Damage level & Ripple effect \\
\hline High & $\begin{array}{l}\text { Damage to information related to operations and system control } \\
\text { such as control information and operation information, or } \\
\text { personal information }\end{array}$ & The damage can spread to a city or large areas \\
Middle & $\begin{array}{l}\text { Damage to setup information such as devices, systems, services, } \\
\text { protocols }\end{array}$ & $\begin{array}{l}\text { The damage can spread to relevant systems, devices, } \\
\text { protocols, } \\
\text { and services, as well as peripheral systems and devices }\end{array}$ \\
& $\begin{array}{l}\text { Damage to information related to small amounts of data, etc., } \\
\text { among general statistical data and data collected from multiple }\end{array}$ & $\begin{array}{l}\text { The damage occurs only to the relevant systems, } \\
\text { devices, protocols, services, etc. }\end{array}$ \\
& sensors for generation of statistics & \\
\hline
\end{tabular}


Table 4.Criteria for evaluating the accessibility, physical security level and the spreading level of device damage at the installation site

\begin{tabular}{|c|c|c|c|}
\hline Grade & Accessibility & Physical security level & Spreading level of device damage \\
\hline High & $\begin{array}{l}\text { Installed in an external space that is } \\
\text { easily accessible by anyone }\end{array}$ & $\begin{array}{l}\text { Personal authentication devices such as } \\
\text { biometrics and access card and physical } \\
\text { security devices such as CCTV that are } \\
\text { operated } 24 / 7 \text { are installed. }\end{array}$ & $\begin{array}{l}\text { The damage is spread to a city or } \\
\text { larger areas. }\end{array}$ \\
\hline Middle & $\begin{array}{l}\text { Installed in an external space, but it } \\
\text { is accessible only by the help of } \\
\text { special equipment } \\
\text { Installed in an independent space or } \\
\text { in a space whose entrance is easily } \\
\text { accessible by anyone }\end{array}$ & $\begin{array}{l}\text { There are physical locking devices such as } \\
\text { padlocks, and physical security devices are } \\
\text { constructed in such a manner that, although } \\
\text { CCTVs exist, } 24 / 7 \text { monitoring is not } \\
\text { performed. }\end{array}$ & $\begin{array}{l}\text { The damage is spread to the } \\
\text { relevant devices and some } \\
\text { peripheral devices. }\end{array}$ \\
\hline Low & $\begin{array}{l}\text { Installed in an independent space } \\
\text { that is accessible only by limited } \\
\text { people }\end{array}$ & $\begin{array}{l}\text { There are no special physical security } \\
\text { devices except for locks for devices and } \\
\text { systems. }\end{array}$ & $\begin{array}{l}\text { Services can be provided even if } \\
\text { the devices do not work. }\end{array}$ \\
\hline
\end{tabular}

Table 5. Criteria for importance of standard targets

\begin{tabular}{ll}
\hline Grade & Importance of standard targets \\
\hline High & The damage is spread to a city or larger areas. \\
Middle & The damage is spread to the relevant device and some peripheral devices. \\
Low & Services can be provided even if the devices do not work. \\
\hline
\end{tabular}

Table 6. Criteria for risk estimation for standard targets depending on the identification of security threats

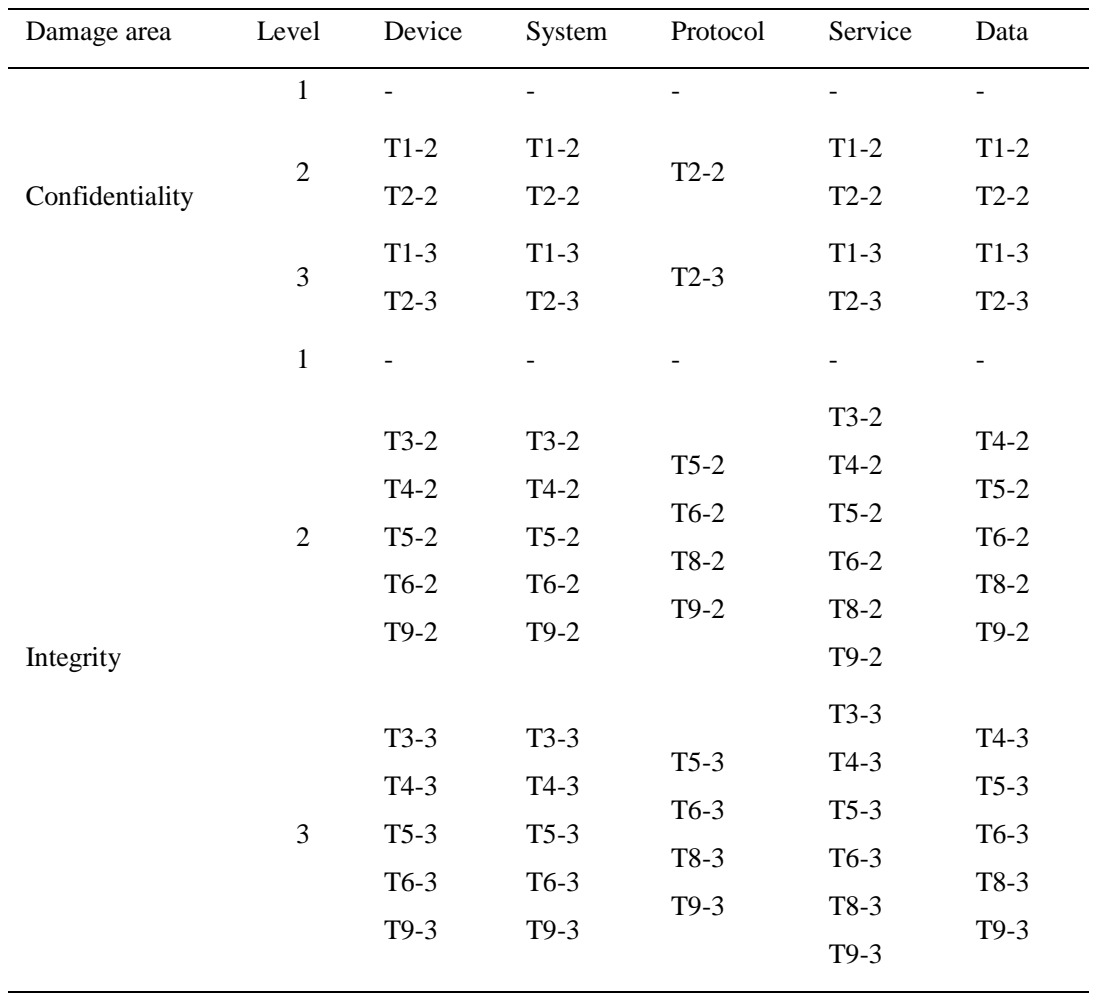




\begin{tabular}{ccccccc}
\hline \multirow{2}{*}{1} & $\mathrm{~T} 7-1$ & $\mathrm{~T} 7-1$ & & $\mathrm{~T} 10-1$ & $\mathrm{~T} 10-1$ \\
& $\mathrm{~T} 10-1$ & $\mathrm{~T} 10-1$ & & & \\
& & $\mathrm{~T} 3-2$ & $\mathrm{~T} 3-2$ & & $\mathrm{~T} 3-2$ & $\mathrm{~T} 3-2$ \\
Availability & 2 & $\mathrm{~T} 7-2$ & $\mathrm{~T} 7-2$ & $\mathrm{~T} 11-2$ & $\mathrm{~T} 10-2$ & $\mathrm{~T} 10-2$ \\
& & $\mathrm{~T} 10-2$ & $\mathrm{~T} 10-2$ & & $\mathrm{~T} 11-2$ & $\mathrm{~T} 11-2$ \\
& $\mathrm{~T} 11-2$ & $\mathrm{~T} 11-2$ & & & \\
& & $\mathrm{~T} 3-3$ & $\mathrm{~T} 3-3$ & & $\mathrm{~T} 3-3$ & $\mathrm{~T} 3-3$ \\
& $\mathrm{~T} 7-3$ & $\mathrm{~T} 7-3$ & & $\mathrm{~T} 10-3$ & $\mathrm{~T} 10-3$ \\
& $\mathrm{~T} 10-3$ & $\mathrm{~T} 10-3$ & & $\mathrm{~T} 11-3$ & $\mathrm{~T} 11-3$ \\
& $\mathrm{~T} 11-3$ & $\mathrm{~T} 11-3$ & & & \\
\hline
\end{tabular}

\section{Risk Evaluation Based on the Structure of the Power Information Control System}

This chapter evaluates the risk based on the security threats for each component of the power information control system by applying the criteria defined in the smart grid security standard mentioned in Chapter 3.

\subsection{Identification of security threats for each component of the power information control system}

The security threats of each component of the power information control system were identified based on 11 security threats. First of all, Table 7 shows the threats of security violations for information (T1 T6) among the 11 security threats. In Table 7, importance was applied as the top criterion for the damage level and ripple effect. Furthermore, the information assets were matched to (T1) to (T6) depending on the presence or absence of the security threat, and the standard security threat was determined as the top criterion.

Table 7. Identification of security threats of the power information control system related to information

\begin{tabular}{lccccccccc}
\hline Target & Damage level & Ripple effect & importance & T1 & T2 & T3 & T4 & T5 & T6 \\
\hline EMS & High & High & High & T1-3 & - & T3-3 & T4-3 & - & - \\
SCADA & High & High & High & T1-3 & - & T3-3 & T4-3 & - & - \\
MTU & Middle & High & High & T1-2 & T2-3 & T3-2 & T4-2 & T5-3 & T6-3 \\
RTU & Middle & Middle & Middle & - & T2-3 & - & - & T5-3 & T6-3 \\
FD & Low & Low & Low & - & T2-2 & - & - & T5-2 & T6-2 \\
\hline
\end{tabular}

Next, Table 8 shows the identification of physical access security threats, and Tables 9 and 10 show the identification of security threats (T10) and (T11), respectively. Finally, the unauthorized access to network (T8) and the denial of act (T9) are defined in Table 11.

Table 8. Physical access security threats

\begin{tabular}{llll}
\hline Target & Place risk & Damage spreading & T7 \\
\hline EMS & Low & High & T7-1 \\
SCADA & Low & High & T7-1 \\
MTU & Middle & Middle & T7-2 \\
RTU & Middle & Middle & T7-2 \\
FD & High & Low & T7-2 \\
\hline
\end{tabular}


Table 9. Threats for using prohibited features

\begin{tabular}{llll}
\hline Target & Function type & Accessibility & T10 \\
\hline EMS & Active control & Impossible & - \\
SCADA & Active control & & - \\
\hline MTU & Active control & & T10-2 \\
RTU & Passive control & Possible & T10-1 \\
FD & Data collection & & T10-1 \\
\hline
\end{tabular}

Table 10. Treats for using excessive resources

\begin{tabular}{llll}
\hline Target & Resource type & $\begin{array}{l}\text { Importance of } \\
\text { standard target }\end{array}$ & T11 \\
\hline EMS & System & High & T11-3 \\
SCADA & System & High & T11-3 \\
MTU & Device & Middle & T11-2 \\
RTU & Device & Middle & T11-2 \\
FD & Device & Low & T11-2 \\
\hline
\end{tabular}

Table 11. Threats for unauthorized access to network and denial of act

\begin{tabular}{lll}
\hline Target & $\begin{array}{l}\text { Unauthorized access } \\
\text { to network (T8) }\end{array}$ & Denial of act (T9) \\
\hline EMS & T8-3 & T9-3 \\
SCADA & T8-3 & T9-3 \\
MTU & T8-2 & T9-2 \\
RTU & T8-2 & T9-2 \\
FD & T8-2 & T9-2 \\
\hline
\end{tabular}

\subsection{Risk evaluation of the power information control system}

This chapter summarizes the security threats identified in Chapter 4.1 in a single table and the risk of each component of the power information control system is estimated. EMS and SCADA were classified as systems, and MTU, RTU, and FD were classified as devices. Then the risk of each component was estimated. For EMS and SCADA, the risks of confidentiality, integrity, and availability were all estimated as level 3. For MTU, RTU, and FD, which were classified as devices, the risks were estimated as level 3 for confidentiality and integrity and level 2 for availability.

Table 12. Risk of EMS

\begin{tabular}{|c|c|c|c|c|c|c|c|c|c|c|c|c|c|}
\hline \multicolumn{2}{|l|}{ Security threat } & $\mathrm{T} 1$ & $\mathrm{~T} 2$ & T3 & $\mathrm{T} 4$ & $\mathrm{~T} 5$ & T6 & $\mathrm{T} 7$ & $\mathrm{~T} 8$ & T9 & $\mathrm{T} 10$ & T11 & EMS \\
\hline \multicolumn{2}{|c|}{ Security threat level } & $\mathrm{T} 1-3$ & - & T3-3 & $\mathrm{T} 4-3$ & - & - & $\mathrm{T} 7-1$ & $\mathrm{~T} 8-3$ & T9-3 & - & $\mathrm{T} 11-3$ & Risk \\
\hline \multirow{4}{*}{$\begin{array}{l}\text { Security } \\
\text { service } \\
\text { violation risk }\end{array}$} & $\begin{array}{l}\text { Confid } \\
\text { entialit }\end{array}$ & 3 & - & - & - & - & - & - & - & - & - & - & 3 \\
\hline & $\mathrm{y}$ & & & & & & & & & & & & \\
\hline & $\begin{array}{l}\text { Integrit } \\
\mathrm{y}\end{array}$ & - & - & 3 & 3 & - & - & - & - & 3 & - & - & 3 \\
\hline & $\begin{array}{l}\text { Availa } \\
\text { bility }\end{array}$ & - & - & - & - & - & - & 1 & - & - & - & 3 & 3 \\
\hline
\end{tabular}


Table 13 Risk of SCADA

\begin{tabular}{|c|c|c|c|c|c|c|c|c|c|c|c|c|c|}
\hline \multicolumn{2}{|l|}{ Security threat } & $\mathrm{T} 1$ & $\mathrm{~T} 2$ & T3 & $\mathrm{T} 4$ & T5 & T6 & $\mathrm{T} 7$ & T8 & T9 & T10 & $\mathrm{T} 11$ & SCAD \\
\hline \multicolumn{2}{|c|}{ Security threat level } & $\mathrm{T} 1-3$ & - & T3-3 & $\mathrm{T} 4-3$ & - & - & $\mathrm{T} 7-1$ & T8-3 & T9-3 & - & $\mathrm{T} 11-3$ & A Risk \\
\hline \multirow{5}{*}{$\begin{array}{l}\text { Security } \\
\text { service } \\
\text { violation risk }\end{array}$} & Confid & & & & & & & & & & & & \\
\hline & entialit & 3 & - & - & - & - & - & - & - & - & - & - & 3 \\
\hline & $\mathrm{y}$ & & & & & & & & & & & & \\
\hline & $\begin{array}{l}\text { Integrit } \\
\mathrm{y}\end{array}$ & - & - & 3 & 3 & - & - & - & - & 3 & - & - & 3 \\
\hline & $\begin{array}{l}\text { Availa } \\
\text { bility }\end{array}$ & - & - & - & - & - & - & 1 & - & - & - & 3 & 3 \\
\hline \multicolumn{14}{|c|}{ Table 14. Risk of MTU } \\
\hline \multicolumn{2}{|l|}{ Security threat } & $\mathrm{T} 1$ & $\mathrm{~T} 2$ & T3 & $\mathrm{T} 4$ & T5 & T6 & $\mathrm{T} 7$ & $\mathrm{~T} 8$ & T9 & T10 & T11 & MTU \\
\hline \multicolumn{2}{|c|}{ Security threat level } & $\mathrm{T} 1-2$ & $\mathrm{~T} 2-3$ & T3-2 & $\mathrm{T} 4-2$ & T5-3 & T6-3 & $\mathrm{T} 7-2$ & T8-2 & T9-2 & $\mathrm{T} 10-2$ & $\mathrm{~T} 11-2$ & Risk \\
\hline \multirow{3}{*}{$\begin{array}{l}\text { Security } \\
\text { service } \\
\text { violation } \\
\text { risk }\end{array}$} & $\begin{array}{l}\text { Confide } \\
\text { ntiality }\end{array}$ & 2 & 3 & - & - & - & - & - & - & - & - & - & 3 \\
\hline & $\begin{array}{l}\text { Integrit } \\
\mathrm{y}\end{array}$ & - & - & 2 & 2 & 3 & 3 & - & - & 2 & - & - & 3 \\
\hline & $\begin{array}{l}\text { Availab } \\
\text { ility }\end{array}$ & - & - & - & - & - & - & 2 & - & - & 2 & 2 & 2 \\
\hline
\end{tabular}

Table 1.5 Risk of RTU

\begin{tabular}{|c|c|c|c|c|c|c|c|c|c|c|c|c|c|}
\hline \multicolumn{2}{|c|}{ Security threat } & $\mathrm{T} 1$ & $\mathrm{~T} 2$ & $\mathrm{~T} 3$ & $\mathrm{~T} 4$ & $\mathrm{~T} 5$ & T6 & $\mathrm{T} 7$ & $\mathrm{~T} 8$ & T9 & $\mathrm{T} 10$ & $\mathrm{~T} 11$ & RTU \\
\hline \multicolumn{2}{|c|}{ Security threat level } & - & $\mathrm{T} 2-3$ & - & - & T5-3 & T6-3 & $\mathrm{T} 7-2$ & $\mathrm{~T} 8-2$ & T9-2 & T10-1 & T11-2 & Risk \\
\hline \multirow{3}{*}{$\begin{array}{l}\text { Security } \\
\text { service } \\
\text { violation } \\
\text { risk }\end{array}$} & $\begin{array}{l}\text { Confid } \\
\text { entialit } \\
\mathrm{y}\end{array}$ & - & 3 & - & - & - & - & - & - & - & - & - & 3 \\
\hline & $\begin{array}{l}\text { Integrit } \\
\mathrm{y}\end{array}$ & - & - & - & - & 3 & 3 & - & - & 2 & - & - & 3 \\
\hline & $\begin{array}{l}\text { Availab } \\
\text { ility }\end{array}$ & - & - & - & - & - & - & 2 & - & - & 1 & 2 & 2 \\
\hline
\end{tabular}

Table 16. Risk of FD

\begin{tabular}{|c|c|c|c|c|c|c|c|c|c|c|c|c|c|}
\hline \multicolumn{2}{|c|}{ Security threat } & $\mathrm{T} 1$ & $\mathrm{~T} 2$ & T3 & $\mathrm{T} 4$ & T5 & T6 & $\mathrm{T} 7$ & $\mathrm{~T} 8$ & $\mathrm{~T} 9$ & $\mathrm{~T} 10$ & T11 & FD \\
\hline \multicolumn{2}{|c|}{ Security threat level } & - & $\mathrm{T} 2-3$ & - & - & T5-3 & T6-3 & $\mathrm{T} 7-2$ & T8-2 & T9-2 & $\mathrm{T} 10-1$ & $\mathrm{~T} 11-2$ & Risk \\
\hline \multirow{3}{*}{$\begin{array}{l}\text { Security } \\
\text { service } \\
\text { violation } \\
\text { risk }\end{array}$} & $\begin{array}{l}\text { Confide } \\
\text { ntiality }\end{array}$ & - & 3 & - & - & - & - & - & - & - & - & - & 3 \\
\hline & $\begin{array}{l}\text { Integrit } \\
\mathrm{y}\end{array}$ & - & - & - & - & 3 & 3 & - & - & 2 & - & - & 3 \\
\hline & $\begin{array}{l}\text { Availab } \\
\text { ility }\end{array}$ & - & - & - & - & - & - & 2 & - & - & 1 & 2 & 2 \\
\hline
\end{tabular}

\section{Conclusion}

This study identified the cyber threats of a power information control system, and estimated the risk to each component of the system.

To estimate the security risk of each component, this study applied the standardization target identification criteria and security threat identification criteria presented in the smart grid security standard. To analyze the estimated risks, the EMS and SCADA, which were classified as systems, were 
estimated to have the highest level of security service violation risk. Thus, more detailed security measures should be prepared for the identified security threats. Furthermore, MTU, RTU, and FD, which were classified as devices, were estimated to have risk level 3for confidentiality and integrity and risk level 2 for availability. In particular, the MTU requires more diverse security measures compared to other devices because it was identified in every security threat owing to its functional characteristics. The results of this study can be used as basic data for establishing the security requirements of a smart grid and will provide a basis for rational decision making in the development of a cyber security system that reflects the characteristics of the power system operating system. In follow-up research, more meaningful results could be obtained by establishing guidelines for security measures based on the risk for each component of the power information control system.

\section{Acknowledgements}

This research was supported by Basic Science Research Program through the National Research Foundation by the Ministry of Education (grant number. NRF-2015R1D1A1A01057823)

\section{References}

[1] National Intelligence Service. National information protection white paper 2016. September 2017.

[2] Negrete-Pincetic M, Yoshida F, Gross G. Towards quantifying the impacts of cyber attacks in the competitive electricity market environment. Presented at: PowerTech, 2009 IEEE Bucharest.

[3] Hwang SS, Woo PS, Choi S, Kim BH. Analysis of the impact of cyber attacks on energy management system in smart grid environment. International Journal of Smart Grid and Clean Energy, 2016; 5(4): 245-251.

[4] Lee KS. A study on KEPCO AMI system security policy in compliance with domestic legal regulations and standards. MS thesis. Department of Cyber Security, Korea University. Korea; 2015.

[5] Woo PS. A study on quantitative methodology to assess cyber security risks of SCADA systems. MS thesis. Department of Electrical and Control Engineering, Hongik University. Korea; 2014.

[6] Woo PS, Hwang SS, Hwang SH, Kim BH. Risk Assessment for Secruity of Power Information Control System. International Journal of Smart Grid and Clean Energy, 2018.

[7] Korea Smart Grid Association. Requirements for Ensuring of Smart Grid Standards (SGSF-121-1-1). SmartGrid Standardization Forum, 2014. 